\title{
A Palliative Approach to Neurological Care: A Literature Review
}

\author{
Teneille E. Gofton, Mandar S. Jog, Valerie Schulz
}

\begin{abstract}
This review assesses the current opinion towards early palliative care in neurology and discusses the existing evidence base. A comprehensive literature search resulted in 714 publications with 53 being directly relevant to the scope of this review. The current literature reflects primarily expert opinion and describes a growing interest in the early introduction of palliative principles into neurological care. Early initiation of palliative interventions has the potential to improve quality of life, enhance symptom management and assist in advance care planning. Further data is required to determine whether this shift in philosophy has a positive impact on patient care.
\end{abstract}

RÉSUMÉ: Revue de la littérature portant sur l'approche palliative aux soins neurologiques. Cette revue évalue l'opinion actuelle concernant les soins palliatifs précoces en neurologie et discute des données actuelles à l'appui. Une recherche étendue de la littérature a permis d'identifier 714 publications dont 53 étaient directement pertinentes au sujet de cette revue. La littérature actuelle reflète surtout l'opinion d'experts et témoigne d'un intérêt croissant pour l'introduction précoce des principes de soins palliatifs dans les soins neurologiques. Un début précoce d'interventions palliatives peut améliorer la qualité de vie, améliorer la gestion des symptômes et aider à la planification des soins à un stade plus avancé de la maladie. Il faudra recueillir plus de données pour déterminer si ce changement philosophique a un impact positif sur les soins aux patients.

Can. J. Neurol. Sci. 2009; 36: 296-302

Neurological diseases present and progress with great clinical variation. In contrast to patients in many other areas in medicine, neurological patients frequently live many years while developing cumulative physical and cognitive disabilities ${ }^{1}$. As a result, patients living with neurological disease cope with decreasing quality of life before reaching the terminal stage of their illness ${ }^{2,3}$.

Palliative care addresses the physical and psychological aspects of end of life. The World Health Organization defines palliative care as:

"an approach that improves the quality of life of patients and their families facing the problem associated with life-threatening illness, through the prevention and relief of suffering by means of early identification and impeccable assessment and treatment of pain and other problems, physical, psychosocial and spiritual. Palliative care: provides relief from pain and other distressing symptoms; affirms life and regards dying as a normal process; intends neither to hasten or postpone death; integrates the psychological and spiritual aspects of patient care; offers a support system to help patients live as actively as possible until death; offers a support system to help the family cope during the patients illness and in their own bereavement; uses a team approach to address the needs of patients and their families, including bereavement counseling, if indicated; will enhance quality of life, and may also positively influence the course of illness; is applicable early in the course of illness, in conjunction with other therapies that are intended to prolong life, such as chemotherapy or radiation therapy, and includes those investigations needed to better understand and manage distressing clinical complications" ${ }^{4}$.

Palliative care was originally developed around terminal cancer care, but its principles are applicable to neurological illness. The incorporation of the principles of palliative care into neurology is an emerging field. An area of great interest is the palliation of specific symptoms during the terminal phase of neurological disease (i.e. approximately the final two weeks of

From the Department of Clinical Neurosciences (TEG, MSJ, VS), Department of Anesthesia (VS), University of Western Ontario, London Health Sciences Centre, London, Ontario, Canada.

Received September 4, 2008. Final Revisions Submitted December 19. 2008 Correspondence to: Teneille E. Gofton, University of Western Ontario, London Health Sciences Centre, 339 Windemere Road, London, Ontario, N6A 5A5, Canada. 
life). Some literature also supports incorporating palliative care principles into the care of patients living with advanced dementia and amyotrophic lateral sclerosis (ALS) prior to terminal illness ${ }^{5}$. Significantly less data exists with respect to other chronic neurological illnesses. Kristjanson et $\mathrm{al}^{6}$, among others, suggest introducing palliative care in neurology prior to the terminal stage. The purpose of studying an earlier integration of palliative care into the ongoing care of patients living with neurodegenerative diseases is to determine if such an approach will improve quality of life and symptom management.

Through a review of the medical literature, this paper discusses the current opinions with respect to the integration of palliative principles into neurological care prior to the immediately terminal stages of disease.

\section{Methods}

Search Strategy: PubMED, EMBASE, SUMSearch and the Cochrane Library were searched using the following search terms (as key words, MeSH terms in PubMED or subheadings in EMBASE): neurology, nervous system diseases, palliative, palliative therapy, palliative care, hospices, terminal care, terminal illness, end of life, end of life care, withholding treatment, autoimmune diseases of the nervous system, peripheral nervous system diseases, autonomic nervous system diseases and heredodegenerative disorders of the nervous system. No date or language limitations were used. Combinations of the previously outlined terms yielded 714 publications.

Inclusion Criteria: Publications included addressed the topic of a palliative approach to the neurological patient prior to terminal stage (i.e. the final two weeks of life). Studies and editorials from all health care disciplines, including medicine, nursing and psychology, were considered.

Exclusion Criteria: Many publications were excluded because of the a priori scope of this review. Publications solely about pain control or withdrawal of care, euthanasia and assisted suicide were excluded as were publications not dealing specifically with neurology or dealing mainly with ethical or legal concepts in palliative care. Publications assessing a single therapeutic intervention, addressing active disease management, encompassing only the last few weeks of life or addressing educational issues were excluded.

Of the 714 publications found, 53 were considered to be pertinent to the scope of this review. Bibliographies from all 53 publications were also reviewed yielding no further pertinent articles.

\section{Literature OVERVIEW}

Fifty-three publications met the inclusion criteria for systematic review. The studies were published between 1995 and

Table 1: Identification of original research regarding a palliative approach to the care of patients living with chronic neurodegenerative diseases

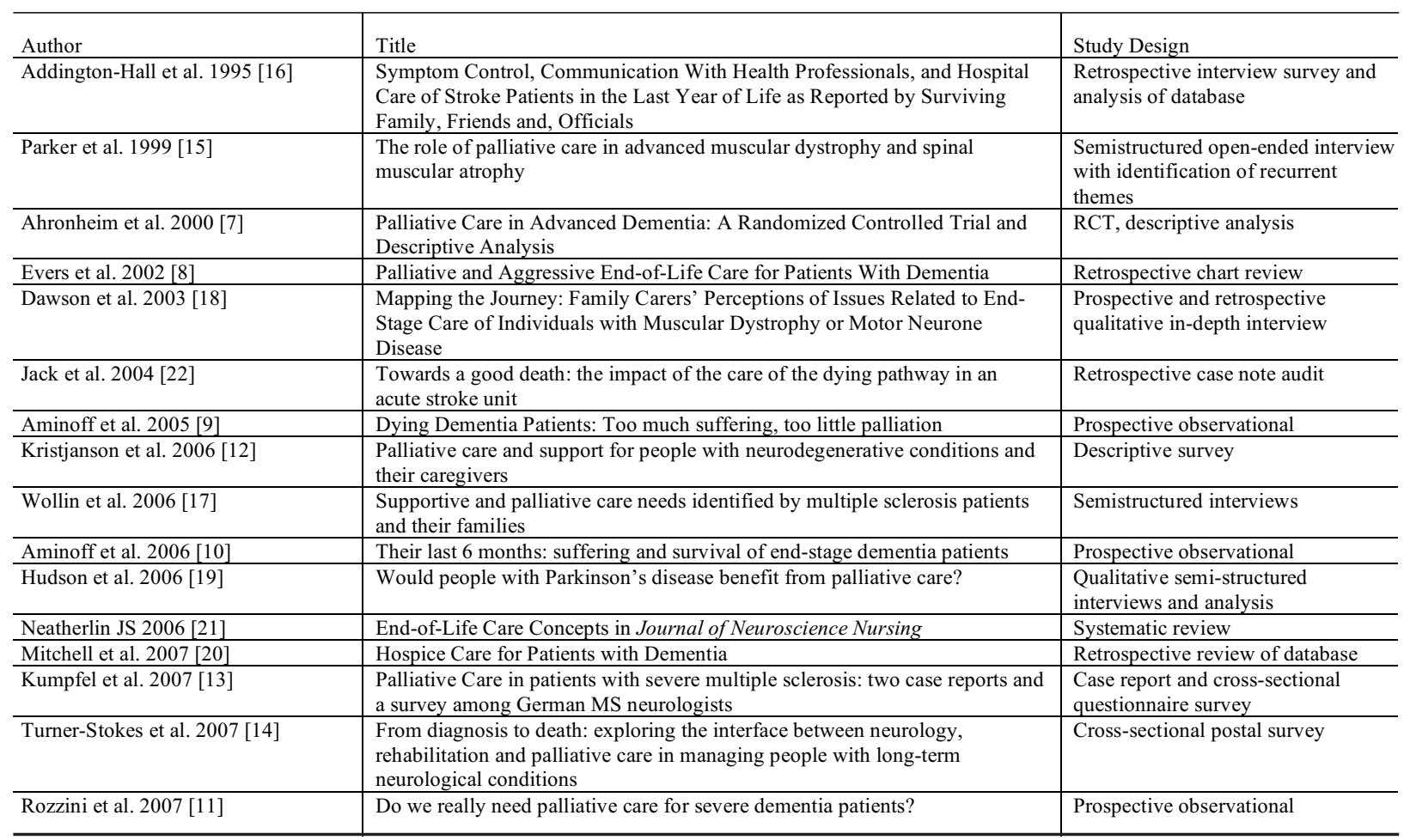

$\mathrm{RCT}=$ randomized, controlled trial 
2007 and originated from Europe, North America and Japan. English translations, if available, or the English abstract were obtained for all articles. There were 16 original research studies (Table 1), 27 reviews (4 systematic reviews, 23 overviews); (Table 2), 8 editorials; (Table 3), 1 program description and 2 position statements.

\section{Original Research}

Sixteen original research articles were considered. Of these articles, there was one randomized-controlled trial $^{7}$, four prospective observational studies ${ }^{8-11}$, three postal survey or questionnaire based studies ${ }^{12-14}$, five structured or semistructured qualitative interview studies ${ }^{15-19}$, one retrospective database analysis ${ }^{20}$, one descriptive data collection from the literature $^{21}$ and one uncontrolled intervention study ${ }^{22}$.

The single randomized-controlled trial addressed the impact of a palliative team intervention versus no intervention during an acute hospitalization in patients with advanced dementia ${ }^{7}$. The intervention consisted of recommendations by a palliative team with the aim of enhancing patient comfort. Ahronheim et al demonstrate no overall statistical benefit to consultation by an inpatient palliative team for acutely hospitalized patients with advanced dementia ${ }^{7}$. The negative results of this study are in contrast to the current opinion (discussed below) and there are several potential causes for the lack of effect. Potential causes intrinsic to dementia include: difficulty in predicting prognosis in advanced dementia and difficulty in assessing patient comfort in advanced dementia ${ }^{7}$. In addition, it appears that study patients were cared for by the same primary care team, regardless of randomization. Therefore, approaches learned from the palliative intervention and intentionally applied to patients in the intervention group may have been unintentionally applied to patients randomized to no additional intervention, thereby creating a form of crossover effect. Furthermore, there was a lack of continuity of care after hospital discharge and between admissions, which may lead to a reduced effect size. At baseline, five patients in the intervention group had a living will while no patients in the control group had a living will $(\mathrm{p}<0.02)^{7}$. Despite the negative statistical results, it is of note that twice the number of patients in the control group underwent mechanical ventilation as compared to the intervention group and that one patient in the control group received a tracheostomy. Cardiopulmonary resuscitation (CPR) was avoided completely in the intervention group, while three patients in the control group were administered CPR.

Three observational studies were included. One study showed that patients with advanced dementia were equally likely to receive aggressive end-of-life care (e.g. intravenous antibiotics)

Table 2: Identification of reviews regarding a palliative approach to the care of patients living with chronic neurodegenerative diseases

\begin{tabular}{|c|c|c|}
\hline Study & Title & Study Design \\
\hline Von Gunten et al. 1996 [48] & Terminal care for noncancer patients & Review \\
\hline Borasio et al. 1997 [27] & Palliative care in amyotrophic lateral sclerosis & Review \\
\hline Voltz et al. $1997[29]$ & Palliative therapy in the terminal stage of neurological disease & Review \\
\hline Foley et al. $2001[33]$ & Palliative care in neurology & Review \\
\hline Ben-Zacharia et al. 2001 [49] & Palliative care in patients with multiple sclerosis & Review \\
\hline Volpe B $2001[50]$ & Palliative treatment for stroke & Review \\
\hline Moskowitz et al. 2001 [51] & Palliative care for people with late-stage Huntington's disease & Review \\
\hline Kristjanson et al. 2003 [1] & $\begin{array}{l}\text { New dimensions in palliative care: a palliative approach to neurodegenerative } \\
\text { diseases and final illness in older people }\end{array}$ & Review \\
\hline Taillibert et al. 2004 [47] & Palliative care in patients with primary brain tumors & Review \\
\hline Sachs et al. 2004 [32] & Barriers to excellent End-of-life Care for Patients with Dementia & Review \\
\hline Burgess et al. 2004 [52] & Addressing the palliative care needs of people with dementia & Review \\
\hline Thomas et al. 2004 [53] & Parkinson's disease, palliative care and older people: Part 1 & Review \\
\hline Weidner NJ 2005 [40] & $\begin{array}{l}\text { Developing an interdisciplinary palliative care plan for the patient with muscular } \\
\text { dystrophy }\end{array}$ & Review \\
\hline Sampson et al. 2005 [23] & $\begin{array}{l}\text { A systematic review of the scientific evidence for the efficacy of a palliative } \\
\text { approach in advanced dementia }\end{array}$ & Systematic review \\
\hline Chang et al. 2005 [24] & $\begin{array}{l}\text { Palliative care for end-stage dementia: A discssion of the implications for } \\
\text { education of health care professionals }\end{array}$ & Systematic review \\
\hline Kristjanson et al. 2005 [54] & $\begin{array}{l}\text { End-of-life challenges in residential aged care facilities: a case for a palliative } \\
\text { approach to care }\end{array}$ & Review \\
\hline Owens et al. $2005[41]$ & Integrating Palliative and Neurological Critical Care & Review \\
\hline Kim et al. 2005 [34] & End-of-life Care for Persons with Alzheimer's Disease & Review \\
\hline Bunting-Perry LK 2006 [37] & Palliative Care in Parkinson's Disease: Implications for Neuroscience Nursing & Review \\
\hline Roger KS 2006 [55] & A literature review of palliative care, end of life, and dementia & Review \\
\hline Small N 2007 [35] & $\begin{array}{l}\text { Living well until you die: quality of care and quality of life in palliative and } \\
\text { dementia care }\end{array}$ & Review \\
\hline Wolf-Klein et al. 2007 [38] & Conceptualizing Alzheimer's Disease as a Terminal Medical Illness & Review \\
\hline Liao et al. $2007[30]$ & Attitudinal Differences in Neurodegenerative Disorders & Review \\
\hline Travers et al. $2007[36]$ & Palliative care provision in Huntington's disease & Review \\
\hline Stevens et al. $2007[25]$ & Palliative care in stroke: a critical review of the literature & Systematic review \\
\hline Harris D 2007 [31] & Forget me not: palliative care for people with dementia & Review \\
\hline Saleem et al 2007 [26] & $\begin{array}{l}\text { Symptom prevalence among people affected by advanced and progressive } \\
\text { neurological conditions }\end{array}$ & Systematic review \\
\hline
\end{tabular}


Table 3: Identification of editorials outlining expert opinion with respect to a palliative approach to the care of patients living with chronic neurodegenerative diseases.

\begin{tabular}{l|l}
\hline Author & Title \\
\hline $\begin{array}{l}\text { Hurley et al. 2000 } \\
\text { 42] }\end{array}$ & $\begin{array}{l}\text { End-of-life care for patients with } \\
\text { advanced dementia }\end{array}$ \\
\hline $\begin{array}{l}\text { Peterson K 2001 } \\
{[56]}\end{array}$ & Finding the Balance \\
\hline $\begin{array}{l}\text { Borasio et al. 2005 } \\
{[43]}\end{array}$ & Palliative Care in Neurology \\
\hline $\begin{array}{l}\text { Kristjanson et al. } \\
2005 \text { [6] }\end{array}$ & $\begin{array}{l}\text { Expanding the boundaries of Palliative } \\
\text { Care: an Australian Perspective }\end{array}$ \\
\hline $\begin{array}{l}\text { Graham et al. 2005 } \\
{[44]}\end{array}$ & $\begin{array}{l}\text { Integrating Palliative Care into Chronic } \\
\text { Care for Children with Severe }\end{array}$ \\
\hline $\begin{array}{l}\text { Arbour et al. 2005 } \\
\text { N7] }\end{array}$ & $\begin{array}{l}\text { Neurodevelopmental Disabilities } \\
\text { Many Contributions }\end{array}$ \\
\hline $\begin{array}{l}\text { Hertogh CM 2006 } \\
{[58]}\end{array}$ & $\begin{array}{l}\text { Advance care planning and the relevance } \\
\text { of a palliative care approach in dementia }\end{array}$ \\
\hline
\end{tabular}

as those without dementia, but that they were less likely to receive aggressive pain control during the same period ${ }^{8}$. Another group showed that higher scores on the Mini Suffering State Examination (MSSE) scale in terminal demented patients were associated with end stage dementia. Serial MSSE administration may help identify the dementia patients most at risk of dying and therefore most likely to benefit from a preterminal palliative care intervention $^{9,10}$. Rozzini et al demonstrated that in hospitalized patients with dementia, being bedridden is independently associated with six-month mortality $(65 \%$ greater risk of mortality $)^{11}$. Thus, being permanently bedridden may identify dementia patients most likely to benefit from palliative intervention.

Eight qualitative postal surveys and semi-structured interview techniques targeted a variety of populations to identify unmet needs in patients with neurodegenerative diseases. At least $50 \%$ more palliative care supports are available to patients with ALS than to those with other neurodegenerative disorders. Fewer patients with multiple sclerosis (MS) have a caregiver compared to other neurological patients $(50 \% \text { versus } 70-90 \%)^{12}$. In all neurodegenerative diseases studied, patients and caregivers feel that information about the disease, equipment for daily living, ongoing support workers and financial assistance for care should be priorities ${ }^{12}$. The most frequent unmet needs of patients with MS are psychological support, availability of physical and occupational therapists, palliative care, spiritual support and access to nurses and physicians ${ }^{13}$. Significant barriers to coordinated care identified are limited palliative care resources and a lack of neurological expertise amongst palliative physicians ${ }^{14}$. In patients dying from stroke, muscular dystrophy (MD) and motor neuron disease (MND), areas in need of improvement were symptom management, psychological support, bereavement care both prior to and following death and assistance with advance planning ${ }^{15,16,18}$. Outpatient populations with MS or Parkinson's disease (PD) had similar needs ${ }^{17,19}$. Patients experienced difficulties with the psychological impact of diagnosis, financial hardship, management of physical challenges and isolation from supports (both health related and social).

A retrospective database review demonstrated that while most families are satisfied with the end-of-life care, they would benefit from more information about the dying process, increased emotional supports and better coordination of care $^{20}$.

\section{REVIEWS}

Twenty-five prior review articles were assessed in this study of the literature (4 systematic reviews, 22 overviews; Table 2). The specific management of terminal symptoms such as shortness of breath, death rattle, restlessness, delirium, seizures and pain will not be further discussed in this review. The majority of the review articles describe the eventual course and specific symptom management of the different neurological illnesses. Many articles allude to a palliative approach to overall care. Only four systematic reviews provided a comprehensive description of the literature search and explicit inclusion and exclusion criteria for the selected articles ${ }^{23-25}$.

The four systematic reviews include an analysis of the existing literature regarding a palliative approach in dementia $^{23,24}$, palliative care in stroke ${ }^{25}$ and symptom prevalence in neurological populations ${ }^{26}$. Sampson et al considered four papers investigating the efficacy of a palliative care approach in the care of patients with dementia ${ }^{23}$. Research in the dementia population is methodologically difficult given issues of consent and the challenges inherent to evaluating the efficacy of end-oflife care in a population of patients in which communication barriers exist. Chang et al addressed the challenges to the provision of palliative care in patients with dementia and the current educational needs of health care providers in this area ${ }^{24}$. They identified a need for further palliative education in dementia health care professionals and for improved access to palliative care professionals ${ }^{24}$. Stevens et al aimed to identify the palliative care needs of stroke patients ${ }^{25}$. The appraisal identified little data identifying the palliative care needs of this patient population.

Saleem et al performed a comprehensive review of the literature to identify the extent of symptoms in patients with neurological disease ${ }^{26}$. They demonstrated that the following symptoms are common to multiple neurological disorders at severe or advanced stages: mobility problems, communication, weakness, spasm/stiffness, swallowing, bowel/constipation, bladder problems, depression and psychiatric problems. Saleem et al suggest that a common approach to the management of these symptoms is likely to benefit patients with a variety of disorders ${ }^{26}$. In addition to the similarities, most neurological diseases had specific individual symptoms, requiring special attention.

It remains difficult to predict the appropriate time to preemptively initiate palliative interventions. Outside of ALS, there are few neurological diseases with observational data allowing for prediction of disease progression and for prognostication $^{27,28}$. Monitoring the development of specific symptoms, such as respiratory symptoms, can help indicate to 
the health care team the appropriate timing for initiation of end of life discussions ${ }^{29}$.

The difficulty in determining prognosis remains a significant barrier to the initiation of palliative care ${ }^{30}$. However, as stated by Liao et al, this difficulty in determining prognosis is yet another reason for palliative services to be involved in patient care ${ }^{30}$. In addition, the needs of patients living with different neurological illnesses may vary ${ }^{30}$. Further observational data is needed in order to determine specific disease features that may foreshadow the accumulation of disability $25,29,31$. Other perceived barriers to the provision of effective palliative care include the view that diseases such as dementia and PD, among others, do not cause death and are not terminal illnesses ${ }^{24,32}$. These difficulties limit access to palliative care and hospice supports ${ }^{24,33}$, which impacts patients and caregivers alike a $^{34,35}$.

Issues such as advance directives and living wills should be addressed at an earlier stage in patients living with neurodegenerative disorders. Not only does this allow families time to adjust to anticipated changes, but it also allows patients to discuss their wishes while they remain intellectually capable $1,27,28,36-38$. Cognitive impairment also complicates the assessment and management of disease symptoms over time ${ }^{32}$. Studies indicate that more patients with dementia experience pain in the last six months of life than do patients with terminal cancer, despite similar end of life needs ${ }^{36,39}$.

Some recent reviews advocate for the incorporation of a palliative approach to neurological care from the time of diagnosis. This promotes an active approach to symptom management ${ }^{1}$. It allows physicians to develop stronger and more trusting relationships with patients in anticipation of end of life care $^{40}$. Further, because of a heavy symptom burden many elements of palliative care are applicable to the care of the neurological patient while disease modifying treatments are being pursued, even where a cure exists ${ }^{33,40,41}$. The main focus of a palliative approach to neurological disease is to maintain dignity and increase hope through the disease process by adequately managing physical, psychological and existential suffering while assisting with decision making processes ${ }^{1,40,41}$. Because neurologists may be the primary physician involved in coordinating the care of patients with neurological illnesses, increased palliative care training would likely be of significant benefit to neurologists ${ }^{32}$.

\section{EDITORIALS}

There is a growing consensus that a palliative approach to the care of the neurological patient will lead to enhanced symptom control during the stages of active disease management, to improved end of life care during the later stages and to increased patient and family support throughout the disease course. Kristjanson et al outlined a staged approach to palliation in neurology including a palliative care approach, in which provision of active disease management is ongoing and provided alongside palliative care; specialist palliative care services, in which a specialist palliative care team is consulted regarding difficult to control symptoms and support; and end of life or terminal care, in which the final days or weeks of life are reached and the focus is on ameliorating the dying person's comfort ${ }^{6}$. Similar barriers to integration of palliative care into neurology, as previously discussed, were identified in the editorials ${ }^{42-44}$.

\section{OTHER}

The search also identified a program description ${ }^{45}$ and two position statements ${ }^{46}$. The program description was of the Palliative Excellence in Alzheimer Care Efforts program ${ }^{45}$, a program designed to integrate palliative care methods into the primary care of patients with dementia, including advance planning, patient-centered care family support and a palliative care focus from the time of diagnosis through to the terminal stages of disease. Both the American Academy of Neurology and the Study Group of Bioethics and Palliative Care in Neurology have published position statements. Defanti et al propose an expanded definition of palliative care and role for palliative care in neurology while continuing to pursue curative approaches ${ }^{46}$. Furthermore, Defanti et al discuss that many neurological disorders are chronic and progressive but not necessarily fatal. Precisely identifying the appropriate time to initiate a palliative approach to the neurological patient remains a challenge ${ }^{46}$.

\section{DISCUSSION}

The current expert opinion strongly supports an earlier introduction of palliative care principles into neurological care. There is a need for enhanced symptom management, improved advance care planning and better prognostication. However, evidence based data is necessary in order to support this strategy.

In neurology, there are currently many disorders without curative treatments. Fortunately, new disease modifying therapies are under continuous development. The importance of new therapies must be highlighted and should not be deemphasized. Concurrent implementation of palliative principles along with active disease management has the potential to benefit many patients with neurological disorders, especially those with neurodegenerative disorders. The current expert opinion reflects a growing interest in this area and thus a perceived need on the part of health care professionals. The early incorporation of palliative care into neurology requires further study. Both qualitative and quantitative data are necessary to further support early palliative intervention. However, challenges in studying palliative care in neurology do exist. There are few reliable outcome assessment tools and identification of the pre-terminal versus terminal stages can be difficult. These challenges in both study design and outcome assessment are highlighted in the negative randomized controlled trial by Ahronheim et $\mathrm{al}^{7}$. While this study does not achieve statistical significance, in a population with end stage dementia felt to be in the final stages of life, there were fewer non palliative interventions (mechanical ventilation, tracheostomy and cardiopulmonary resuscitation) in the palliative intervention group. Emerging research regarding patient needs in stroke, MD, MS, PD and MND suggests that despite differing disease courses, there are similar psychosocial and physical needs ${ }^{15-19}$. Even with current symptom and psychosocial management strategies, studies show that patients need enhanced social, spiritual and therapy supports ${ }^{12,13}$.

Recent data collected by Saleem et al establishes that many neurological disorders have common symptoms during advanced disease stages and may benefit from a common approach ${ }^{26}$. However, there are also symptoms specific to individual neurological illness that will likely need a targeted approach. 
Identifying common symptoms in advanced neurological disease could allow the evidence for management of these symptoms to be explored and expanded. At present, few validated and reliable quality of life and outcome assessment tools exist for use in the various neurodegenerative diseases ${ }^{31,47}$. The current lack of tools makes it difficult to effectively evaluate the impact of many palliative interventions. The further development of reliable tools is essential to evaluating the impact of palliative interventions in neurology.

At present the disease trajectory in patients with neurological disorders is difficult to predict and it can be challenging to know when the appropriate time to initiate palliative care principles has been reached. Early data exists for predicting the progression of advanced illness. In bedridden patients with dementia, data shows that life expectancy is less than six months ${ }^{10}$. The MSSE scores can also reflect disease stage in patients with dementia ${ }^{9}$. Data further delineating the disease trajectory and indicators of the terminal stages of the various neurological disorders would be of benefit to patient care. In addition, it is possible that neurological disorders with differing initial trajectories may progress through terminal stages more uniformly once symptoms such as impaired swallowing or immobility have developed.

Earlier advance care planning includes ongoing symptom management, as well as earlier and improved psychosocial supports for patients and caregivers. In many neurological disorders, cognitive impairment becomes a barrier to effective palliation and increases the burden on caregivers. Advanced planning may better prepare patients and their families for future disability and give the patient a more active role in care decisions. Indeed, the literature demonstrates that with advanced care planning patients and caregivers realize the necessity for further support with symptom management, caregiver burden and psychosocial supports ${ }^{12,13,20}$.

\section{CONCLUSION}

Current expert opinion supports an earlier introduction of palliative care principles into neurological care. Further research is needed to strengthen this view. In our opinion, in order to benefit patients and caregivers, improved palliative education is required amongst neurologists and enhanced neurological education is necessary amongst palliative care physicians. Many areas of further research such as observational studies and controlled intervention trials are needed to validate the current literature. By building on our knowledge base in neurology and palliative care, we are likely to improve patient comfort and quality of life.

\section{ACRONYM DEFINITIONS}

ALS - amyotrophic lateral sclerosis; CPR - cardiopulmonary resuscitation; MD - muscular dystrophy; MND - motor neuron disease; MS - multiple sclerosis; MSSE - mini suffering state examination; PD - Parkinson's disease.

\section{ACKNOWLEDGEMENTS}

The authors thank B. Tyson Gofton for ongoing encouragement and for editorial assistance.

\section{REFERENCES}

1. Kristjanson LJ, Toye C, Dawson S. New dimensions in palliative care: a palliative approach to neurodegenerative diseases and final illness in older people. Med J Aust. 2003;179 Suppl 6: S41-3.

2. Gruenewald DA, Higginson IJ, Vivat B, Edmonds P, Burman RE. Quality of life measures for the palliative care of people severely affected by multiple sclerosis: a systematic review. Mult Scler. 2004;10(6):690-704.

3. Jenkinson C, Fitzpatrick R. Reduced item set for the amyotrophic lateral sclerosis assessment questionnaire: development and validation of the ALSAQ-5. J Neurol Neurosurg Psychiatry. 2001;70(1):70-3.

4. WHO Organization WH. Available from: http://www.who.int/ cancer/palliative/definition/ en/. [cited ??? 2008].

5. Borasio GD, Voltz R. [Patient consultation and palliative care in neurology, e.g. in amyotrophic lateral sclerosis]. Internist (Berl). 2000;41(7):627-32.

6. Kristjanson LJ. Expanding the boundaries of palliative care: an Australian perspective. J Palliat Care. 2005;21(3):190-2.

7. Ahronheim JC, Morrison RS, Morris J, Baskin S, Meier DE. Palliative care in advanced dementia: a randomized controlled trial and descriptive analysis. J Palliat Med. 2000;3(3):265-73.

8. Evers MM, Purohit D, Perl D, Khan K, Marin DB. Palliative and aggressive end-of-life care for patients with dementia. Psychiatr Serv. 2002;53(5):609-13.

9. Aminoff BZ, Adunsky A. Dying dementia patients: too much suffering, too little palliation. Am J Hosp Palliat Care. 2005;22 (5):344-8

10. Aminoff BZ, Adunsky A. Their last 6 months: suffering and survival of end-stage dementia patients. Age Ageing. 2006;35 (6):597-601.

11. Rozzini R, Sabatini T, Ranhoff A, Trabucchi M. Do we really need palliative care for severe dementia patients? Age Ageing. 2007;36(5):584-7.

12. Kristjanson LJ, Aoun SM, Oldham L. Palliative care and support for people with neurodegenerative conditions and their carers. Int J Palliat Nurs. 2006;12(8):368-77.

13. Kumpfel T, Hoffmann LA, Pollmann W, Rieckmann P, Zettl UK, Kuhnbach $R$, et al. Palliative care in patients with severe multiple sclerosis: two case reports and a survey among German MS neurologists. Palliat Med. 2007;21(2):109-14.

14. Turner-Stokes L, Sykes N, Silber E, Khatri A, Sutton L, Young E. From diagnosis to death: exploring the interface between neurology, rehabilitation and palliative care in managing people with long-term neurological conditions. Clin Med. 2007;7(2): 129-36.

15. Parker D, Maddocks I, Stern LM. The role of palliative care in advanced muscular dystrophy and spinal muscular atrophy. J Paediatr Child Health. 1999;35(3):245-50.

16. Addington-Hall J, Lay M, Altmann D, McCarthy M. Symptom control, communication with health professionals, and hospital care of stroke patients in the last year of life as reported by surviving family, friends, and officials. Stroke. 1995;26(12): 2242-8.

17. Wollin JA, Yates PM, Kristjanson LJ. Supportive and palliative care needs identified by multiple sclerosis patients and their families. Int J Palliat Nurs. 2006;12(1):20-6.

18. Dawson S, Kristjanson LJ. Mapping the journey: family carers' perceptions of issues related to end-stage care of individuals with muscular dystrophy or motor neurone disease. J Palliat Care. 2003;19(1):36-42.

19. Hudson PL, Toye C, Kristjanson LJ. Would people with Parkinson's disease benefit from palliative care? Palliat Med. 2006;20(2): 87-94.

20. Mitchell SL, Kiely DK, Miller SC, Connor SR, Spence C, Teno JM. Hospice care for patients with dementia. J Pain Symptom Manage. 2007;34(1):7-16.

21. Neatherlin JS, Fox S. End-of-Life care concepts in Journal of Neuroscience Nursing. J Neurosci Nurs. 2006;38(5):342-8, 353. 
22. Jack C, Jones L, Jack BA, Gambles M, Murphy D, Ellershaw JE. Towards a good death: the impact of the care of the dying pathway in an acute stroke unit. Age Ageing. 2004;33(6):625-6.

23. Sampson EL, Ritchie CW, Lai R, Raven PW, Blanchard MR. A systematic review of the scientific evidence for the efficacy of a palliative care approach in advanced dementia. Int Psychogeriatr. 2005;17(1):31-40.

24. Chang E, Hancock K, Harrison K, Daly J, Johnson A, Easterbrook $\mathrm{S}$, et al. Palliative care for end-stage dementia: a discussion of the implications for education of health care professionals. Nurse Educ Today. 2005;25(4):326-32.

25. Stevens T, Payne SA, Burton C, Addington-Hall J, Jones A. Palliative care in stroke: a critical review of the literature. Palliat Med. 2007;21(4):323-31.

26. Saleem T, Leigh PN, Higginson IJ. Symptom prevalence among people affected by advanced and progressive neurological conditions--a systematic review. J Palliat Care. 2007;23(4): 291-9.

27. Borasio GD, Voltz R. Palliative care in amyotrophic lateral sclerosis. J Neurol. 1997;244 Suppl 4:S11-7.

28. Luchins DJ, Hanrahan P, Murphy K. Criteria for enrolling dementia patients in hospice. J Am Geriatr Soc. 1997;45(9):1054-9.

29. Voltz R, Borasio GD. Palliative therapy in the terminal stage of neurological disease. J Neurol. 1997;244 Suppl 4:S2-10.

30. Liao S, Arnold RM. Attitudinal differences in neurodegenerative disorders. J Palliat Med. 2007;10(2):430-2.

31. Harris D. Forget me not: palliative care for people with dementia. Postgrad Med J. 2007;83(980):362-6.

32. Sachs GA, Shega JW, Cox-Hayley D. Barriers to excellent end-oflife care for patients with dementia. J Gen Intern Med. 2004;19 (10):1057-63.

33. Foley KM, Carver AC. Palliative care in neurology. Neurol Clin. 2001;19(4):789-99.

34. Kim KY, Yeaman PA, Keene RL. End-of-life care for persons with Alzheimer's disease. Psychiatr Serv. 2005;56(2):139-41.

35. Small N. Living well until you die: quality of care and quality of life in palliative and dementia care. Ann N Y Acad Sci. 2007;1114: 194-203.

36. Travers E, Jones $\mathrm{K}$, Nichol J. Palliative care provision in Huntington's disease. Int J Palliat Nurs. 2007;13(3):125-30.

37. Bunting-Perry LK. Palliative care in Parkinson's disease: implications for neuroscience nursing. J Neurosci Nurs. 2006;38 (2):106-13.

38. Wolf-Klein G, Pekmezaris R, Chin L, Weiner J. Conceptualizing Alzheimer's disease as a terminal medical illness. Am J Hosp Palliat Care. 2007;24(1):77-82.
39. McCarthy M, Addington-Hall J, Altmann D. The experience of dying with dementia: a retrospective study. Int J Geriatr Psychiatry. 1997;12(3):404-9.

40. Weidner NJ. Developing an interdisciplinary palliative care plan for the patient with muscular dystrophy. Pediatr Ann. 2005;34(7): 546-52.

41. Owens D, Flom J. Integrating palliative and neurological critical care. AACN Clin Issues. 2005;16(4):542-50.

42. Hurley AC, Volicer L, Blasi ZV. End-of-life care for patients with advanced dementia. JAMA. 2000;284(19):2449-50.

43. Borasio GD, Voltz R. Palliative care in neurology. J Palliat Care. 2005;21(3):188-9.

44. Graham RJ, Robinson WM. Integrating palliative care into chronic care for children with severe neurodevelopmental disabilities. J Dev Behav Pediatr. 2005;26(5):361-5.

45. Shega JW, Levin A, Hougham GW, Cox-Hayley D, Luchins D, Hanrahan P, et al. Palliative Excellence in Alzheimer Care Efforts (PEACE): a program description. J Palliat Med. 2003; 6(2):315-20.

46. Defanti CA. Study Group of Bioethics and Palliative Care in Neurology: program document. Neurol Sci. 2000;21(5):261-71.

47. Taillibert S, Laigle-Donadey F, Sanson M. Palliative care in patients with primary brain tumors. Curr Opin Oncol. 2004;16(6): 587-92.

48. von Gunten CF, Twaddle ML. Terminal care for noncancer patients. Clin Geriatr Med. 1996 May;12(2):349-58.

49. Ben-Zacharia AB, Lublin FD. Palliative care in patients with multiple sclerosis. Neurol Clin. 2001 Nov;19(4):801-27.

50. Volpe BT. Palliative treatment for stroke. Neurol Clin. 2001 Nov; 19(4):903-20

51. Moskowitz CB, Marder K. Palliative care for people with late-stage Huntington's disease. Neurol Clin. 2001 Nov;19(4):849-65.

52. Burgess L. Addressing the palliative care needs of people with dementia. Nurs Times. 2004 May 11-17;100(19):36-9.

53. Thomas S, MacMahon D. Parkinson's disease, palliative care and older people: Part 1. Nurs Older People. 2004 Mar;16(1):22-6.

54. Kristjanson LJ, Walton J, Toye C. End-of-life challenges in residential aged care facilities: a case for a palliative approach to care. Int J Palliat Nurs. 2005 Mar;11(3):127-9.

55. Roger KS. A literature review of palliative care, end of life, and dementia. Palliat Support Care. 2006 Sep;4(3):295-303.

56. Peterson K. Finding the balance. Neuro Oncol. 2001 Jan;3(1):55-6.

57. Arbour R, March, K. Neurologic Critical Care: One Focus, Many Contributions. AACN Clinical Issues. 2005;16(4):419-20.

58. Hertogh CM. Advance care planning and the relevance of a palliative care approach in dementia. Age Ageing. 2006 Nov;35(6):553-5. 